\title{
Sistem Informasi Monitoring Kehadiran Siswa dalam Pengawasan Orang Tua pada Sekolah Menengah Kejuruan (SMK) Negeri 4 Banda Aceh
}

\author{
Raihan Islamadina $^{1 *}$, Said Mustafa ${ }^{2}$, dan Saiful Muklis ${ }^{3}$ \\ ${ }^{1}$ Program Studi Pendidikan Teknik Elektro, \\ Fakultas Tarbiyah, UIN Ar Raniry Banda Aceh \\ ${ }^{2,3}$ Program Studi Teknik Komputer \\ Fakultas Teknik Universitas Serambi Mekkah \\ Corresponding author's e-mail: raihanislamadina@ar-raniry.ac.id
}

\begin{abstract}
Abstrak - Sistem absensi pada sebuah lembaga pendidikan merupakan salah satu instrumen dalam menentukan kehadiran peserta didik diberbagai level satuan pendidikan. Di Sekolah Menengah Umum atau di Sekolah Menengah Kejuruan (SMA/SMK), absensi siswa juga menjadi kegiatan rutin yang dilakukan setiap periode pembelajaran. Kurangnya media pendataan, membuat pihak sekolah kesulitan dalam mem-backup data absensi siswa. Manualnya proses absensi siswa juga menjadi salah satu permasalahan yang dihadapi, siswa harus datang langsung ke sekolah untuk mengisi absensi kemudian data tersebut dicatat pada buku besar. Pembuatan laporan yang juga masih manual membuat sering terjadinya kesalahan dalam memasukan data sehingga memerlukan waktu yang lama. Oleh karenanya, tujuan dari penelitian ini adalah membuat sebuah sistem informasi absensi siswa berbasis web menggunakan SMS Gateway untuk memudahkan pendataan absensi berikut dengan databasenya pada Sekolah Menengah Kejuruan (SMK) Negeri 4 Banda Aceh. Penelitian ini menggunakan bahasa pemrograman php dan xampp sebagai web server, serta MySql sebagai databasenya. Penelitian ini menghasilkan sistem informasi absensi siswa berbasis SMS Gateway dengan proses input dan olah data lebih cepat, serta telah diimplementasikan sehingga dapat membantu pihak sekolah dan orang tua siswa dalam proses pengawasan siswa.
\end{abstract}

Kata kunci: sistem informasi, absensi, web, SMS Gateway

\section{Pendahuluan}

Sudah menjadi rutinitas setiap tahun ajaran baru tidak sedikit orang tua mencari sekolah yang terbaik untuk putera-puterinya, sekalipun sekolah yang dipilih nanti biayanya besar dan lokasi yang jauh. Hal tersebut dikerenakan para orang tua menginginkan anaknya di didik oleh sekolah yang baik. Meskipun sudah memilih sekolah terbaik, terkadang lingkungan pergaulan yang kurang baik dapat menyebabkan kenakalan terhadap siswa seperti tidak hadir di kelas (bolos) dan kenakalan lainnya. Hasil dari riset penulis di Sekolah Menengah Kejuruan (SMK) Negeri 4 Banda Aceh yang beralamat di Jl. Sisinga Mangaraja No.109 Banda Aceh, absensi siswa saat ini masih menggunakan sistem manual, dimana orang tua yang ingin mengetahui data kehadiran anaknya di sekolah tersebut harus datang langsung dan mengamati absensi yang telah direkap oleh bagian kesiswaan dalam buku absensi siswa.

Melihat kondisi tersebut, kontrol dari orang tua dan pihak sekolah sangatlah penting sebagai upaya pencegahan terhadap perilaku kenakalan siswa yang tidak diinginkan. Oleh karena itu, penulis membangun sebuah sistem informasi absensi siswa berbasis web yang terintegrasi SMS Gateway pada Sekolah Menengah Kejuruan (SMK) Negeri 4 Banda Aceh menggunakan bahasa pemrograman php dan xampp serta MySql guna mempermudah orang tua dan pihak sekolah dalam mengontrol kehadiran siswanya secara real time yang menyebabkan para siswa akan berfikir dua kali untuk melakukan bolos sekolah dan pelanggaran sekolah lainnya. Selain itu, para orang tua juga akan mengetahui dengan cepat perkembangan absensi atau tingkat kehadiran anaknya tanpa harus datang ke sekolah, sehingga lebih menghemat waktu dan biaya (efisien dan efektif).

\section{Tinjauan Pustaka}

Sistem informasi adalah seperangkat komponen yang saling berhubungan, yang bekerja untuk mengumpulkan dan menyimpan data serta mengolahnya menjadi informasi. Ada lima klasifikasi komponen sistem informasi (gambar 1), yaitu hardware dan software yang berfungsi sebagai mesin, people dan 
procedures yang merupakan manusia dan tata cara menggunakan mesin, data merupakan jembatan penghubung antara manusia dan mesin agar terjadi suatu proses pengolahan data [1].

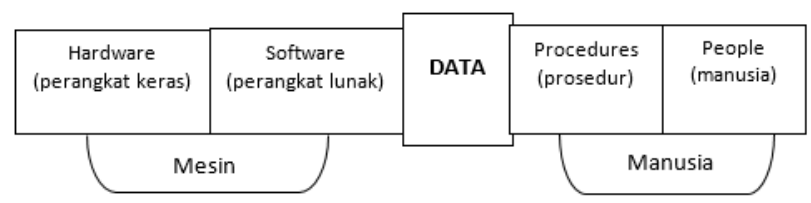

Gambar 1. Lima komponen sistem informasi

Informasi disajikan dengan berbagai macam format data seperti teks, gambar dan video yang dapat diakses menggunakan berbagai aplikasi klien, sehingga memungkinkan penyajian informasi yang lebih menarik dan dinamis dengan pengelolaan yang terorganisasi disebut sebagai website [2],[3].

Informasi dalam format data teks berupa pesan singkat dikirimkan dengan sebuah aplikasi bernama SMS Gateway tanpa perantara ponsel dan internet. Aplikasi ini mengirimkan pesan melalui modem GSM/GPRS dan SIM card. Aplikasi ini bisa mengirimkan pesan privasi begitu juga pesan broadcast secara masal. Aplikasi ini berhubungan langsung dengan mikrokontroler modem dan menggunakan perintah khusus untuk terhubung dengan provider jaringan. SMS gateway juga dapat menampilkan pesan dan melaporkan jumlah pesan tersimpan dan juga pesan terkirim [4].

Penggambaran dan rancangan model sistem Informasi secara logika dapat dibuat dalam bentuk Diagram Konteks dan Diagram Alir Data atau Data Flow Diagram (DFD). Diagram konteks merupakan arus data yang berfungsi untuk menggambarkan keterkaitan aliran-aliran data antar sistem dengan bagian luar (kesatuan luar). Kesatuan luar ini merupakan sumber arus data atau tujuan data yang berhubungan dengan sistem informasi tersebut [1].

Menurut Kustiyaningsih [5], Database adalah struktur penyimpanan data. Untuk menambah, mengakses dan memproses data yang disimpan dalam sebuah komputer, diperlukan sistem manajemen database seperti MySQL server. Menurut Enterprise [6] untuk menampung dan mengatur data yang begitu banyak dapat menggunakan Relational Database Management System (RDBMS) karena semua data disimpan dalam tabeltabel yang berbeda dan dihubungkan berdasarkan relasinya menggunakan primary key dan foreign key. Primary key yaitu suatu aturan yang berguna untuk memastikan bahwa setiap baris data di dalam suatu tabel bersifat unik/berbeda antara baris yang satu dengan yang lainnya sedangkan foreign key berguna untuk mendefinisikan kolom-kolom pada suatu tabel yang nilainya mengacu ke tabel lain [7].

Sebuah aplikasi cross-platform yang digunakan untuk menjembatani/mengomunikasikan antara database SMS Gateway dengan sms devices menggunakan Gammu. Aplikasi gammu berupa daemon yang berjalan secara background. Setiap saat, gammu memonitor sms devices dan database sms gateway. Proses kirim data dengan SMS dari PC secara umum redaksi SMS diubah menjadi format PDU (Protocol Data Unit) dan dikirim oleh mesin handphone kemudian diproses oleh operator dan diterima oleh mesin handphone lagi dalam format PDU dan di ubah menjadi teks oleh handphone. Saat ada sms masuk ke sms devices, maka gammu langsung memindahkannya ke dalam inbox dalam database sms gateway. Sebaliknya saat aplikasi pengirim SMS memasukkan sms ke dalam outbox dalam database sms gateway, maka gammu mengirimkannya melalui sms devices dan memindahkan sms ke sistem dalam database [1].

PHP merupakan salah satu bahasa pemograman server-side di antara beberapa pemograman yang ada. Sejak diluncurkan PHP mendapat respon yang sangat baik dari kalangan pengembang aplikasi web. Kemudahan untuk dipahami, serta sintaknya yang mirip bahasa $\mathrm{C}$ menjadikan pemograman ini cepat dikenal oleh kalangan luas [8].

MySQL (My Structure Query Language) adalah sebuah pogram pembuat database yang bersifat open source. MySQL sebenarnya produk yang berjalan pada platform Linux karena sifatnya open source MySQL dapat dijalankan pada semua platform baik windows maupun Linux. Database MySQL adalah database yang sangat powerfull, stabil, dan mudah [7], [9].

Menurut penelitian [10], HTML (Hyper Text Markup Language) adalah bahasa standar yang digunakan untuk pembuatan halaman web atau word wide web, dengan hypertext dan informasi lain yang akan ditampilkan pada halaman web. Dokumen hypertext bisa berisi text, gambar, dan tipe informasi lain seperti data file, audio, video, dan program executeable.

\section{Metode Penelitian}


Penelitian ini menggunakan software berupa Web Server (Apache) untuk menjalankan aplikasi PHP, Web Browser untuk menampilkan hasil tampilan aplikasi, database MySql (PhpMyadmin) untuk mengola database, Pemograman Client Side (JQuery), dan Personal Home Page (PHP).

\section{Flowmap Sistem Berjalan}

Rancangan ini terdapat beberapa prosedur yang telah dianalisa, yaitu prosedur sistem berjalan dan sistem usulan. Prosedur absensi siswa yang saat ini sedang berjalan dapat dilihat pada gambar 2. Ketika jam pelajaran sudah dimulai, siswa masuk ke dalam kelas, guru atau ketua kelas mengambil absen ke petugas piket yang sudah di serahkan oleh bagian tata usaha dan guru memanggil nama siswa yang tertera di form absensi. Kemudian siswa yang di panggil namanya memberikan jawaban "hadir" dan guru melihat kearah siswa yang menjawab untuk memastikan bahwa yang mejawab "hadir" adalah siswa yang bersangkutan. Ketika sudah dipastikan benar maka guru melakukan ceklist pada form absensi yang menyatakan kehadiran siswa tersebut. Tetapi jika tidak ada yang menjawab maka guru akan mengkonfirmasi apakah ada surat pemberitahuan dari orang tua akan ketidakhadirannya. Jika ada maka guru akan men-ceklist pada kolom ijin atau kolom sakit. Diluar hal diatas ketika tidak ada siswa di kelas dan tidak ada surat keterangan dari orang tua, maka siswa yang bersangkutan dianggap tidak hadir tanpa keterangan "Alpa".

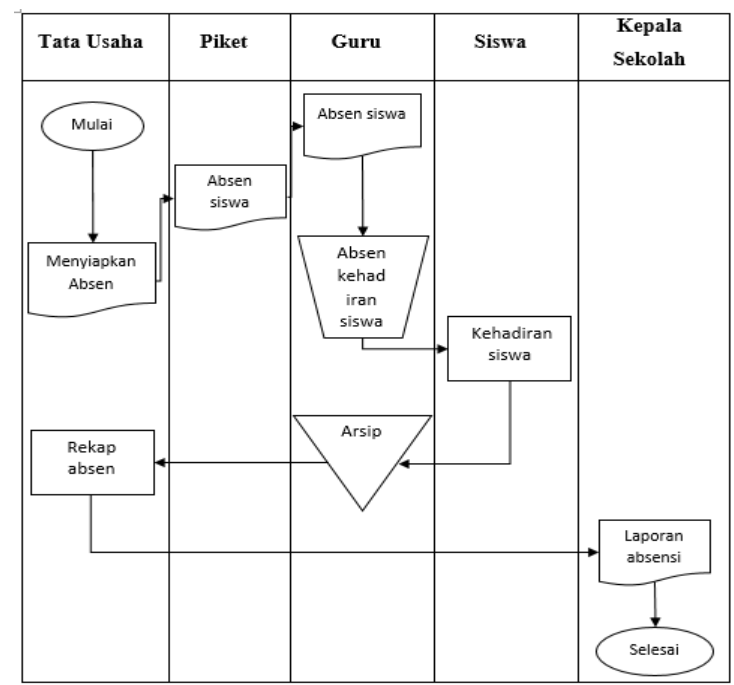

Gambar 2. Flowmap sistem berjalan

\section{Flowmap Sistem Usulan}

Prosedur absensi siswa yang di usulkan dapat dilihat pada gambar 3. Ketika jam pelajaran masuk, guru membuka web absensi yang telah di iputkan data nya oleh admin yang di sini di pegang oleh bagian tata usaha, baik dari data siswa maupun data guru. Guru memanggil nama siswa yang tertera di form absensi, lalu siswa yang di panggil namanya memberikan jawaban "Hadir", ketika guru mendengar ada siswa yang menjawb "Hadir" maka guru tersebut melihat kearah siswa yang menjawab untuk memastikan bahwa yang mejawab "Hadir" bukan siswa lain. Ketika sudah dipastikan benar maka guru melakukan ceklist pada form absensi yang menyatakan kehadiran siswa tersebut. Jika ada siswa yang tidak berhadir (alpa) maka sistem akan mengirimkan pesan kepada nomor handphone orang tua yang tertera pada data siswa. 


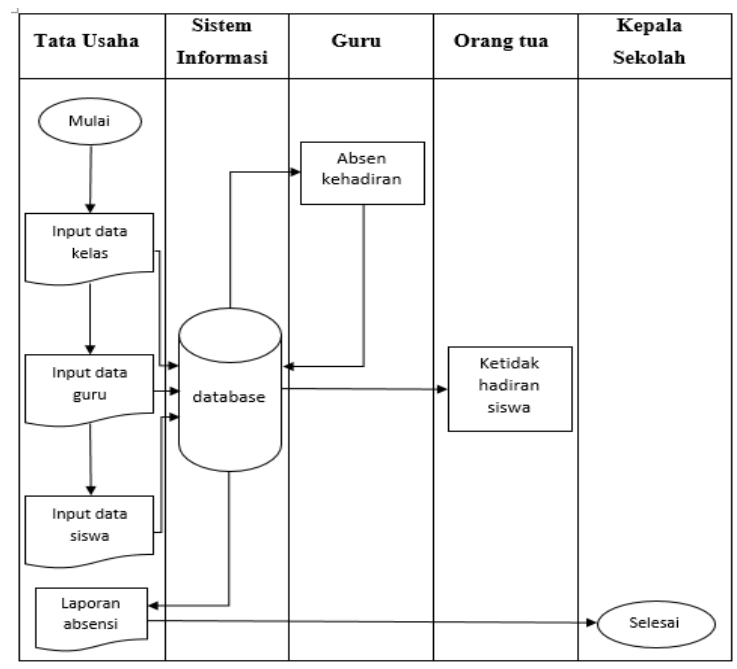

Gambar 3. Flowmap Sistem Usulan

\section{Use Case Diagram}

Use case Diagram merupakan model diagram UML (unified modeling language) yang digunakan untuk menggambarkan requirement fungsional yang dihrapkan dari sebuah sistem. Gambar 4 menjelaskan use case dari rancangan sistem pada penelitian ini yang terdiri dari tiga role user, yaitu:

1. Admin sekolah dapat melakukan regestrasi siswa ke sistem (memasukkan data nomor handphone orang tua siswa) dan input data guru.

2. Guru dapat melakukan presensi ke siswa siswinya bedasarkan mata pelajaran dan jam masuk kelas.

3. Orang tua siswa akan memperoleh sms jika anaknya tidak masuk sekolah pada jam guru yang melakukan absensi.

\section{Digram Konteks}

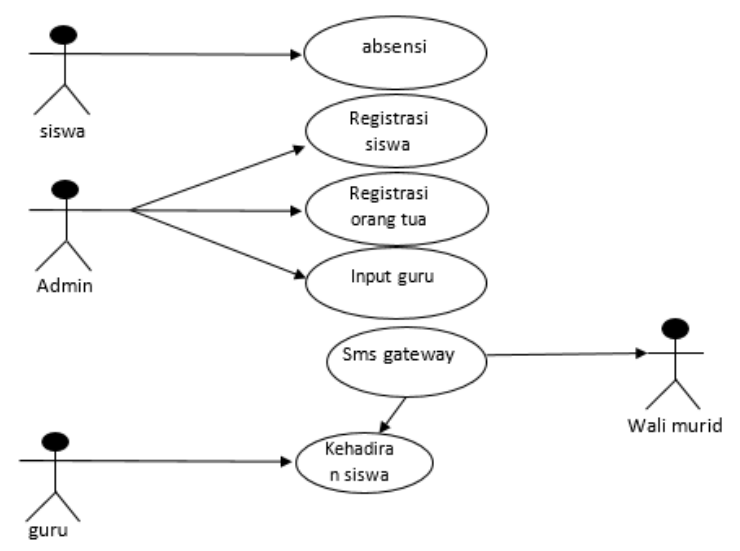

Gambar 4. Use Case Diagram Sistem

Diagram Konteks mencakup satu simbol proses yang mewakili seluruh sistem pengelolaan manajemen presensi dengan empat entitas yang sangat berpengaruh dalam sistem tersebut. Diagram konteks ditampilkan pada gambar 5. Sistem diakses oleh user yaitu admin yang bertugas menginput data user. Sedangkan guru mendata absen siswa dan oranng tua menerima informasi kehadiran siswa. 


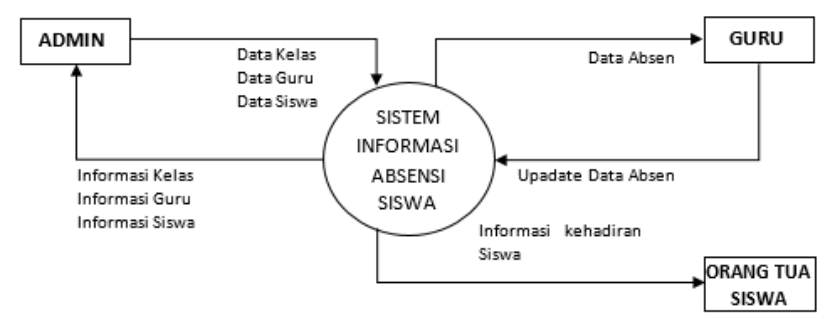

Gambar 5. Diagram konteks

\section{Rancangan Entity Relationship Diagram (ERD)}

Gambar 6 menjelaskan ERD dari sistem monitoring kehadiran siswa SMKN Negeri 4 Banda Aceh dengan data yang saling berhubungan satu dengan lainnya. Setiap guru yang mengajar di kelas memiliki pelajaran dan siswa, dan siswa memiliki absensi kehadiran.

\section{Struktur Database}

Hasil dari Rancangan Entity Relationship Diagram dapat diperluas menjadi rancangan database yang terdiri atas table-tabel yang mempunyai relasi antar table yang terlihat pada tabel di bawah ini:

Tabel 1. User

\begin{tabular}{|r|c|l|r|c|}
\hline No & Field Name & Data Type & Size & Description \\
\hline 1 & Idu & Int & 10 & $($ PK) \\
\hline 2 & Nama & Varchar & 100 & \\
\hline 3 & Pass & Text & & \\
\hline 4 & Level & Varchar & 50 & \\
\hline
\end{tabular}

Tabel 2. Guru

\begin{tabular}{|c|c|l|l|c|}
\hline No & Field Name & Data Type & Size & Description \\
\hline 1 & Idg & Int & 10 & (PK) \\
\hline 2 & Nip & Varchar & 50 & \\
\hline 3 & nama & Varchar & 00 & \\
\hline 4 & jk & Varchar & 3 & \\
\hline 5 & alamat & Text & & \\
\hline 6 & pass & Text & & \\
\hline
\end{tabular}

Tabel 3. Mengajar

\begin{tabular}{|r|c|c|l|c|}
\hline No & Field Name & Data Type & Size & Description \\
\hline 1 & idm & Int & 10 & $(\mathrm{PK})$ \\
\hline 2 & idg & Int & 10 & $(\mathrm{FK})$ \\
\hline 3 & idk & Int & 10 & $(\mathrm{FK})$ \\
\hline
\end{tabular}

Tabel 4. Kelas

\begin{tabular}{|r|c|c|l|c|}
\hline No & Field Name & Data Type & Size & Description \\
\hline 1 & idk & Int & 10 & $(\mathrm{PK})$ \\
\hline 2 & nama & Varchar & 50 & \\
\hline 3 & idp & int & 10 & $(\mathrm{FK})$ \\
\hline
\end{tabular}




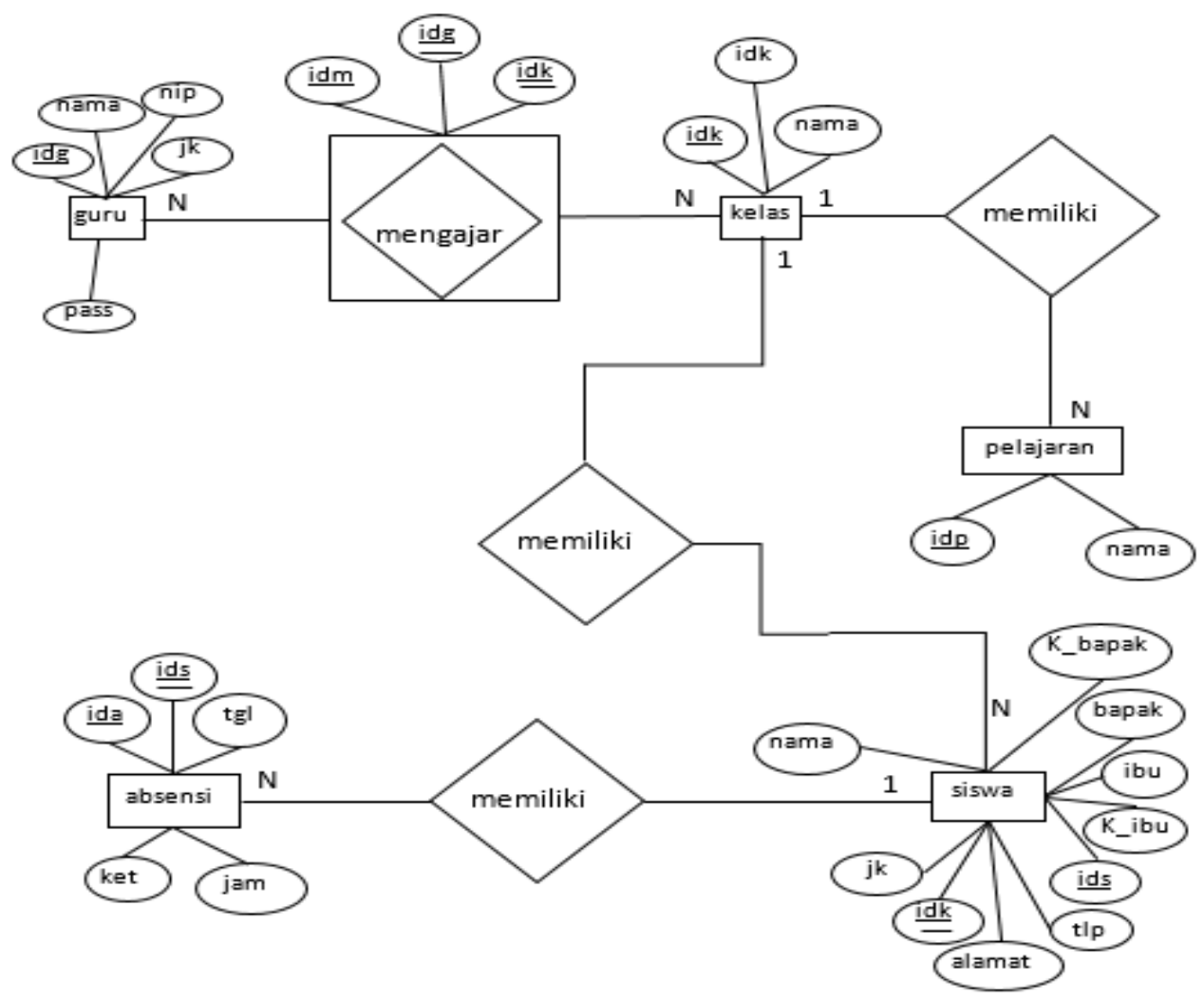

Gambar 6. Entity Relationship Diagram (ERD)

Tabel 5. Siswa

\begin{tabular}{|r|c|c|c|c|}
\hline No Field Name & Data Type & Size & Description \\
\hline 1 & ids & int & 10 & (PK) \\
\hline 2 & nama & Varchar & 100 & \\
\hline 3 & jk & Varchar & 2 & \\
\hline 4 & alamat & text & & \\
\hline 5 & idk & int & 5 & (FK) \\
\hline 6 & tlp & Varchar & 20 & \\
\hline 7 & bapak & Varchar & 50 & \\
\hline 8 & K_bapak & Varchar & 50 & \\
\hline 9 & ibu & Varchar & 50 & \\
\hline 10 & k_ibu & Varchar & 50 & \\
\hline 11 & pass & text & & \\
\hline
\end{tabular}

Tabel 6. Absensi

\begin{tabular}{|r|c|l|l|c|}
\hline No & Field Name & Data Type & Size & Description \\
\hline 1 & ida & int & 10 & (PK) \\
\hline 2 & ids & int & 10 & (FK) \\
\hline 3 & tgl & Varchar & 00 & \\
\hline 4 & ket & Varchar & 3 & \\
\hline 5 & jam & & 3 & \\
\hline
\end{tabular}


Tabel 7. Pelajaran

\begin{tabular}{|r|c|l|l|c|}
\hline No & Field Name & Data Type & Size & Description \\
\hline 1 & idp & int & 10 & (PK) \\
\hline 2 & nama & Varchar & 00 & \\
\hline
\end{tabular}

\section{Hasil dan Pembahasan}

Adapun hasil dari penelitian ini adalah sebagai berikut:

\section{Form Login}

Form login merupakan implementasi dari proses autentikasi pengguna ke dalam sistem informasi. Form login yang ditunjukkan pada gambar 7 dirancang untuk user sebagai pengguna yang mendapatkan menu hak akses dalam menginput data dalam sistem.

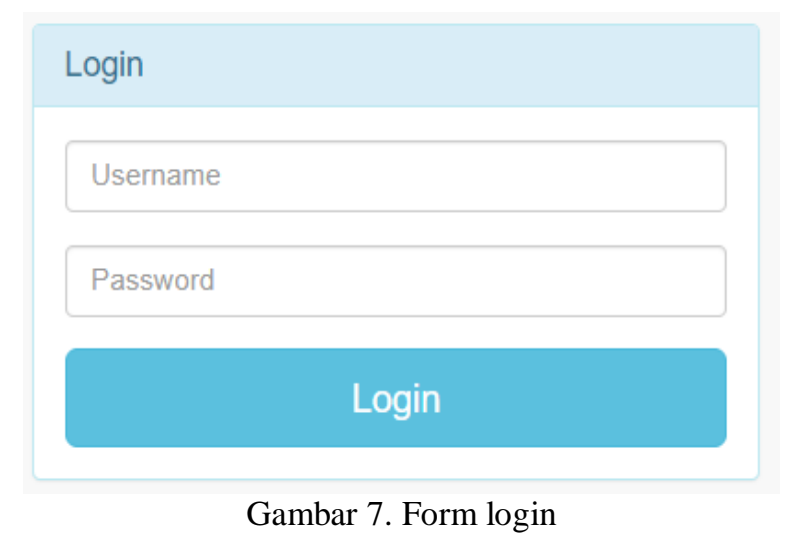

\section{Halaman utama admin}

Halaman utama admin adalah halaman induk yang ditampilkan setelah melakukan proses login dengan sukses. Halaman utama ini memiliki fitur menu yang dapat mengakses dan menampilkan form-form lainnya.

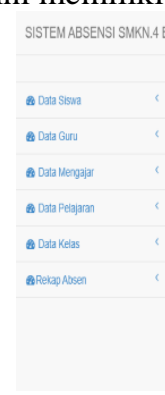

Gambar 8. Halaman utama admin

\section{Form Input siswa}

Form Input siswa terletak pada halaman admin, dan admin pula yang berhak atau bertugas untuk menginput data siswa baru yang terdaftar pada SMKN.4 Banda Aceh. Segala biodata diri di isikan beserta dengan password siswa di kelola oleh orang tua. 


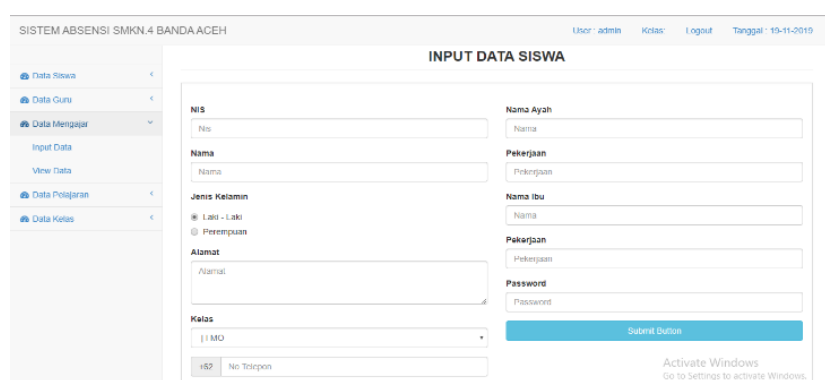

Gambar 9. Form Input siswa

\section{Form input guru}

Form input guru adalah form pengisian data guru yang mengajar. Admin yayng mengelola dan mengisi serta mendaftarkan data guru agar memiliki hak akses terhadap absensi siswa.

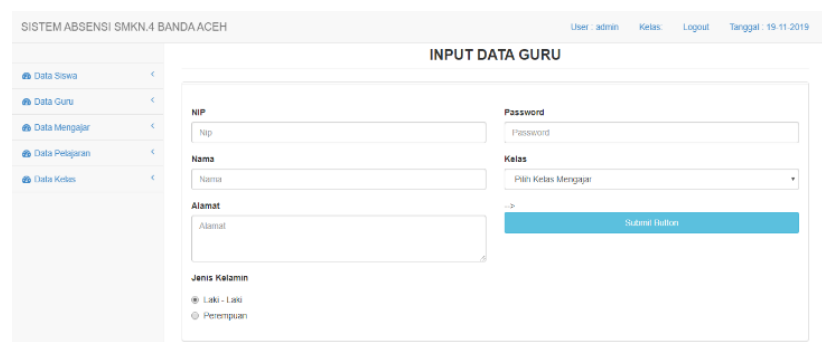

Gambar 10. Form input guru

Form input mengajar

Form input mengajar adalah form untuk menginput data mengajar guru yang sudah di daftrakan oleh admin. Contoh: Guru A mengajar di kelas apa dan pelajaran nya apa, disini tinggal memilih saja karena hanya guru yang sudah terdaftar saja yang mucul pada form.

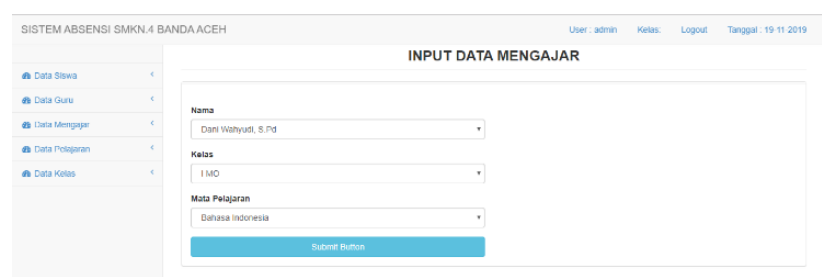

Gambar 11. Form input mengajar

\section{Form input pelajaran}

Form input pelajaran yaitu untuk menginput data pelajaran pada SMKN. 4 Banda Aceh yang terdiri dari kode mata pelajaran dan nama mata pelajaran.

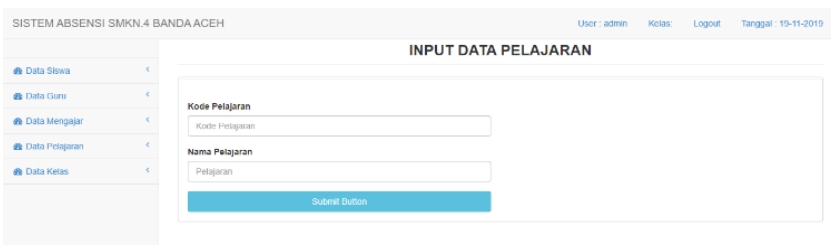

Gambar 12. Form input pelajaran

Form input data kelas

Form input data kelas berfungsi untuk memasukkan data kelas baru jika siswa ramai atau ada jurusan baru pada SMKN.4 Banda Aceh. 


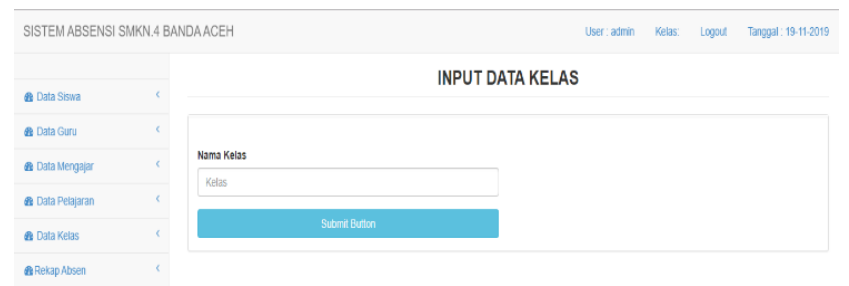

Gambar 13. Form input data kelas

\section{Form pilih absen}

Form pilih absen adalah guru memilih akan mengabsen di kelas mana, pelajaran apa, dan di tanggal, bulan serta tahun berapa. Untuk tanggal, bulan dan tahun secara otomatis mengikuti pada tanggal, bulan dan tahun dimana sistem informasi di buka namun juga dapat di tentukan atau di ubah. Form ini berada pada halaman guru yang sukses untuk login. Pada saat akan meginput absen, maka halaman ini menjadi pembuka dalam memilih absen.

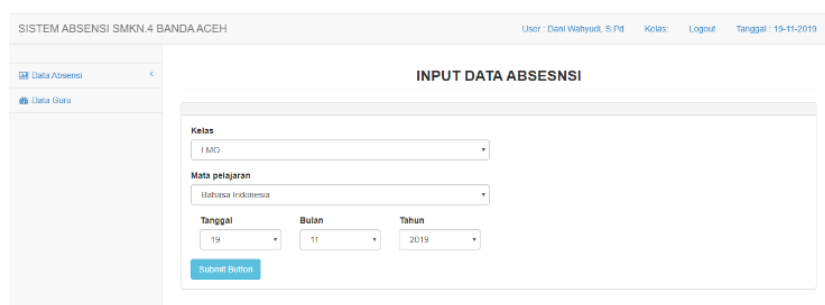

Gambar 14. Form pilih absen

\section{Form input absen}

Form input absen mucul setelah guru memilih absen pada halaman absen. Pada halaman inilah guru akan mengabsen siswanya dengan cara mamanggil siswa lalu memilih tombol yang sesuai dengan keterangan siswa. Disini ada empat tombol absen, yang pertama itu A (alpa), kedua I (izin), ketiga S (sakit) dan terakhir N (netral) atau belum ada keteragan.

Pada halaman ini juga sebelum mengabsen siswa, guru harus terlebih dahulu memilih jam pelajaran yang akan di absen mulai jam ke-1 sampai jam ke-10. Jika sudah selesai mengabsen, maka guru boleh menekan tombol simpan dan data akan disimpan pada database.

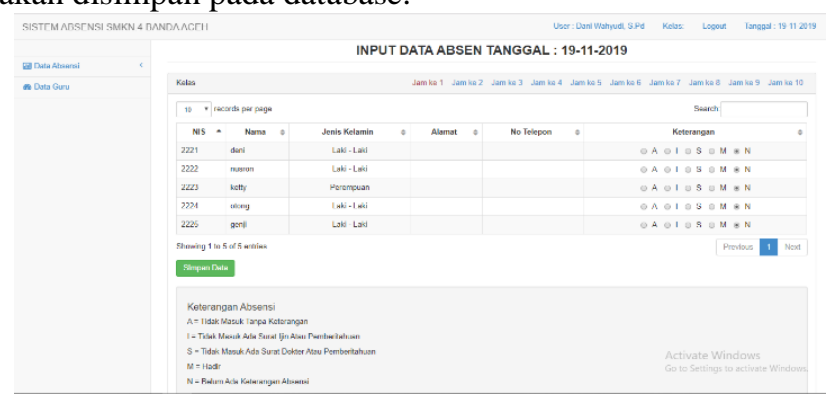

Gambar 15. Form input absen

\section{Form hasil absensi}

Form hasil absensi adalah form yang berada pada halaman akun siswa yang berhasil login. Halaman ini dapat di akses oleh siswa dan orang tua siswa, namun untuk password hanya dapat diubah atas seizin orang tua. Form ini menampilkan data absen siswa si pemilik akun mulai dari pertama masuk sampai akan tamat sekolah. 


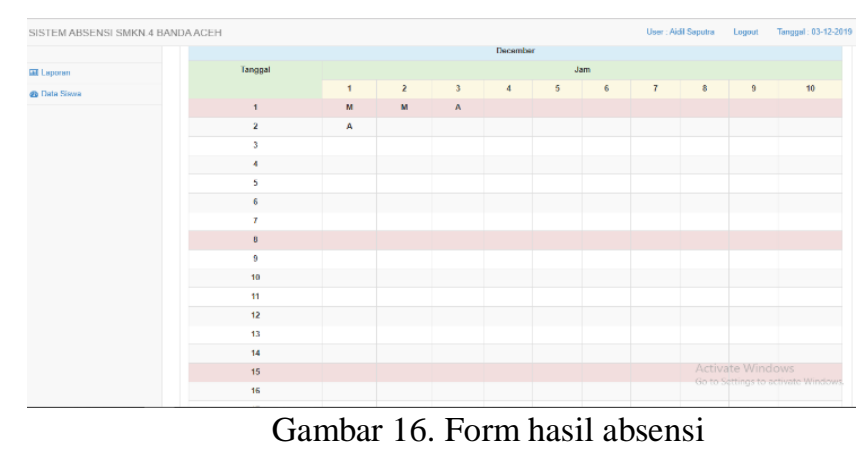

\section{Form data siswa}

Form data siswa adalah form seluruh data siswa yang diinput oleh admin. Form ini juga tersedia tombol edit, hapus, dan detail data siswa. Form ini berada pada halaman admin dan dikeloal oleh admin. Form ini juga menampikan data siswa per-kelas dan form pencarian data.

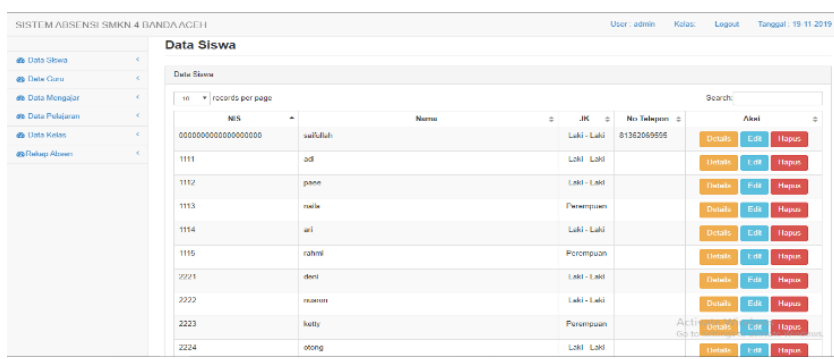

Gambar 17. Form data siswa

\section{Form data guru}

Form data guru adalah form yang manampilkan seluruh data guru yang mengajar pada SMKN.4 Banda Aceh. Sama halnya dengan form data siswa, form ini juga di lengkapi denga tombol edit, hapus, dan detail data guru, serta menampilkan data guru per kelas mengajar.

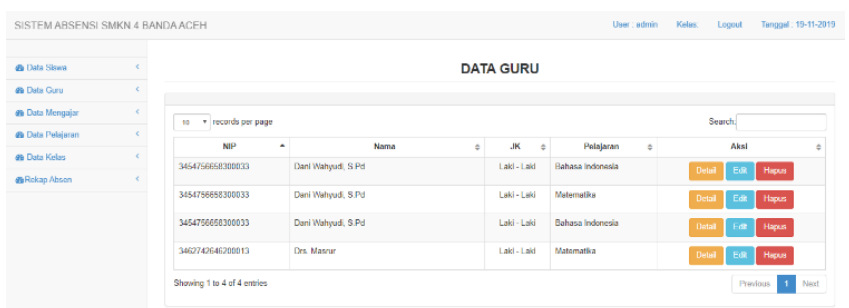

Gambar 18. Form data guru

\section{Form data mengajar}

Form data mengajar yaitu menampilkan data mengajar pada SMKN.4 Banda Aceh. Form ini hanya ada dua tombol yaitu edit dan hapus.

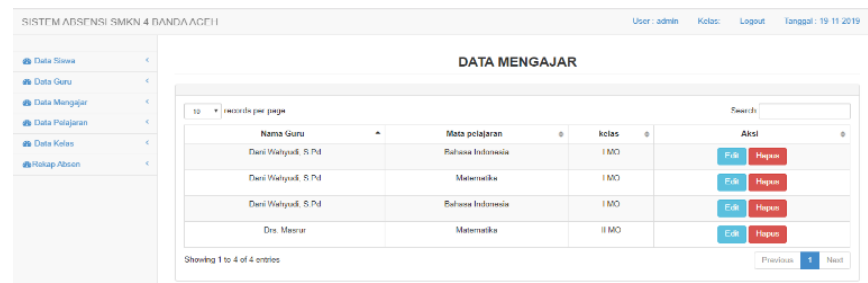

Gambar 19. Form data mengajar 


\section{Form data pelajaran}

Form data pelajaran menampilkan seluruh pelajaran pada SMKN.4 Banda Aceh. Form ini berada pada halaman admin dan hanya memiliki dua tombol, yaitu edit dan hapus.

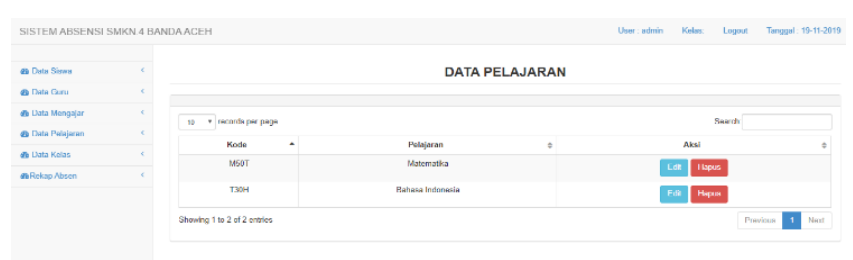

Gambar 20. Form data pelajaran

Form data kelas

Form data kelas menampilkan seluruh data kelas pada SMKN.4 Banda Aceh yang memiliki dua tombol yaitu edit dan hapus.

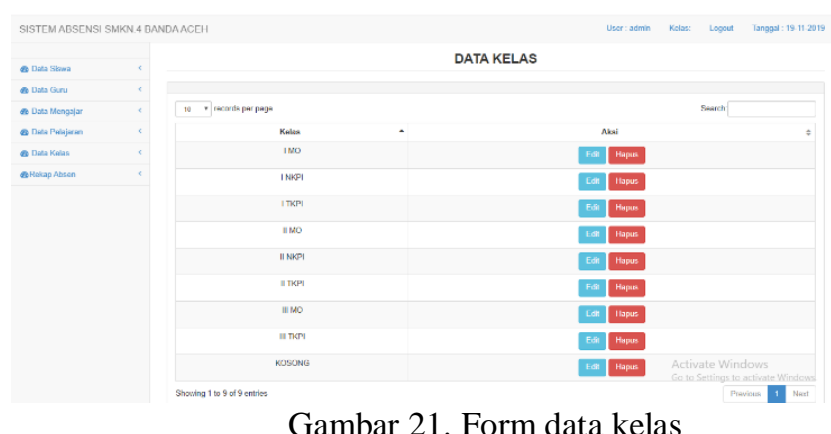

Gambar 21. Form data kelas

\section{Data Rekap}

Data Rekap adalah rekap absen yang memperlihatkan keseluruhan absen pada bulan dan tahun tertentu berdasarkan kelas.

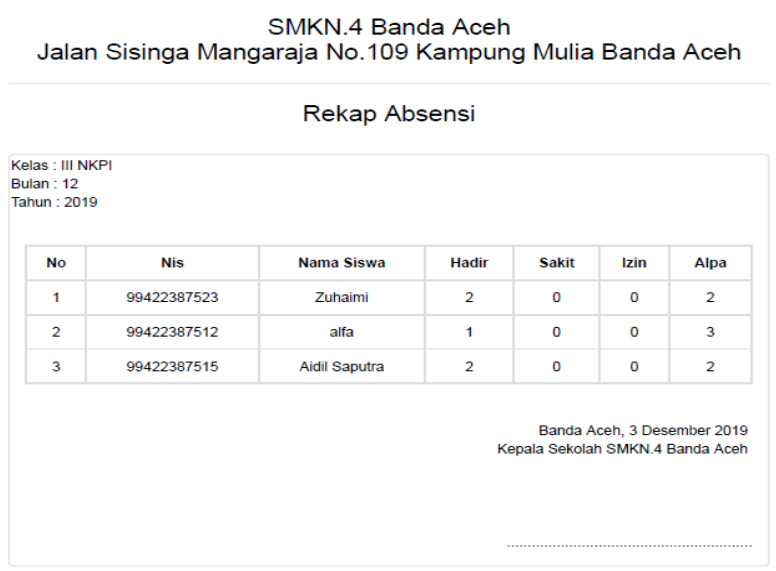

Gambar 22. Data Rekap

\section{Notifikasi sms}

Notifikasi sms adalah bentuk dari tindakan realtime dari sistem informasi kepada orang tua yang anaknya tidak hadir ke sekolah tanpa keterangan (bolos). 


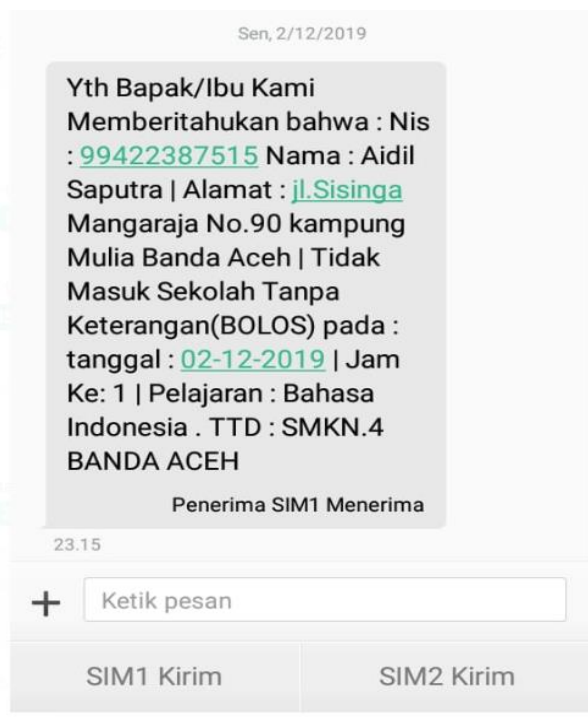

Gambar 23. Notifikasi sms

\section{Kesimpulan}

Berdasarkan hasil penelitian ini, maka dapat disimpulkan bahwa sistem informasi monitoring kehadiran siswa dalam pengawasan orang tua berbasis web dan terintegrasi dengan sms gateway pada SMKN 4 Banda Aceh telah berhasil dibangun dan berjalan dengan sistematis, terstruktur dan terarah, serta berhasil memberikan notifikasi ketidakhadiran siswa kepada orang tua secara realtime, sehingga orang tua dapat berperan aktif dalam pengawasan kehadiran anak di sekolah. Sistem informasi ini juga dapat meningkatkan kinerja menjadi lebih efektif dan efesien bagi guru untuk merekap nilai.

\section{Daftar Pustaka}

[1] R. Islamadina and D. Alfairus, "Sistem Informasi Persediaan Barang Habis Pakai Berbasis SMS Gateway Pada Kantor Camat Seulimuem Kabupaten Aceh Besar," vol. 1, no. 1, pp. 10-16, 2018.

[2] Simarmata, Janner. 2010. Rekayasa Perangkat Lunak. Yogyakarta: Andi Offset.

[3] Hidayat, Rahmat. (2010). Cara Praktis Membangun Website Gratis Jakarta : PT Elex Media Komputindo Kompas, Gramedia.

[4] Goel, Utkarsh., et.all., IEEE (The Institute of Electrical and Electronic Engineers). 2011. "3rd International Conference on Communication Software.” Xi'an, China, 08 September 2011. United Nations: New York.

[5] Kustiyahningsih, Yeni dan Devie Rosa Anamisa, 2011. "Pemograman Web Menggunakan PHP \& $M y S Q L "$. Penerbit : Graha Il Yogyakarta.

[6] Enterprise, Jubilee. 2014. "Trik Praktis Excel untuk Akuntansi”. Penerbit :Elex Media Komputindo. Jakarta.

[7] Budi Raharjo. 2011. “Belajar Otodidak Membuat Database Mengunakan MySQL”.Penerbit: Informatika. Bandung.

[8] Arief, M.Rudyanto. 2011, "Pemrograman Web Dinamis Menggunakan PHP dan MYSQL". Penerbit : Andi Offset. Yogyakarta

[9] Aditya, Alan Nur.2010. “Jago PHP dan MySQL”. Penerbit: Dunia Komputer. Jakarta.

[10]Sutarman. 2012. "Buku Pengantar Teknologi Informasi”. Penerbit : Bumi Aksara. Jakarta. 